Article

\title{
Tension-Stiffening Effect Consideration for Modeling Deflection of Cracked Reinforced UHPC Beams
}

\author{
Le Teng ${ }^{1}$, Rongling Zhang ${ }^{2, *}$ and Kamal Henri Khayat ${ }^{1, *}$ \\ 1 Department of Civil, Architectural and Environmental Engineering, \\ Missouri University of Science and Technology, Rolla, MO 65409-0030, USA; 1th74@mst.edu \\ 2 Department of Civil Engineering, Lanzhou Jiaotong University, Lanzhou 730070, China \\ * Correspondence: mogzrlggg@163.com (R.Z.); khayatk@mst.edu (K.H.K.)
}

check for updates

Citation: Teng, L.; Zhang, R.; Khayat, K.H. Tension-Stiffening Effect Consideration for Modeling Deflection of Cracked Reinforced UHPC Beams. Sustainability 2022, 14, 415. https://doi.org/10.3390/ su14010415

Academic Editor: Igor de la Varga

Received: 14 November 2021

Accepted: 29 December 2021

Published: 31 December 2021

Publisher's Note: MDPI stays neutral with regard to jurisdictional claims in published maps and institutional affiliations.

Copyright: (c) 2021 by the authors Licensee MDPI, Basel, Switzerland. This article is an open access article distributed under the terms and conditions of the Creative Commons Attribution (CC BY) license (https:// creativecommons.org/licenses/by/ $4.0 /)$.

\begin{abstract}
Tension-stiffening effects can significantly influence the flexural performance of cracked reinforced concrete specimens. Such effect is amplified for fiber-reinforced concrete, given the fact that fibers can bridge the cracks. The objective of this study was to develop a model to predict the deflection of cracked reinforced ultra-high performance concrete (R-UHPC) beam elements. The modeling approach characterized the average bending moment of inertia by combining the existing model used for conventional reinforced concrete and the analytical model of stress distribution of UHPC along the cross-section. The finite element analysis (FEA) was employed to evaluate the flexural deflection based on the average bending moment of inertia. The calculated load-deflection relationships have been compared to experimental results. The results indicated that the relative errors of deflection between predicted and experimental results can be controlled within $15 \%$, compared to values ranging from $5 \%$ to $50 \%$ calculated by neglecting the tensile properties of cracked UHPC and values ranging from $5 \%$ to $30 \%$ calculated by effective inertia of bending moment of ACI code. Therefore, the developed model can be used in practice because it can secure the accuracy of deflection prediction of the R-UHPC beams. Such a simplified model also has higher sustainability compared to FEA using solid elements since it is easier and time-saving to be established and calculated.
\end{abstract}

Keywords: cracked beam; flexural strength; inertia of bending moment; tension stiffening; UHPC

\section{Introduction}

Conventional concrete (CC) has a high risk of cracking without a large deformation, resulting in a relatively low structural resiliency and environmental sustainability. For example, the major earthquake or impact loading (i.e., vehicle collision) can lead to fracture failure of CC structures [1,2]. Furthermore, the presence of cracks reduces the durability of concrete and reinforcing steel. The repeated repairs can result in a high carbon and energy footprint. Ultra-high-performance concrete (UHPC) is regarded as a sustainable cementitious composite compared to conventional concrete [3,4]. This is due to the optimized packing density, and low water-to-binder ratio can secure dense microstructure to resist the intrusion of aggressive ions [5-7]. Furthermore, the use of steel fibers can restrain the cracking opening and propagation [8].

The mechanical performance of UHPC can be affected by fiber characteristics, such as shape, length-to-diameter ratio, and volume [9-12]. Wu et al. [10] pointed out that UHPC prepared with $13 \mathrm{~mm}$ hooked fiber exhibited a 10\% higher flexural strength compared to that made with $13 \mathrm{~mm}$ straight fiber. Yoo et al. [11] reported that the increase in fiber length from 13 to $19.5 \mathrm{~mm}$ led to a $35 \%$ increase in flexural strength of UHPC beam specimens. Teng et al. [12] proposed that the flexural strength and toughness can be enhanced by $60 \%$ and $80 \%$, respectively, with the increase in fiber contents from $1 \%$ to $3 \%$. The use of nanofibers can further enhance the mechanical performance of UHPC since they can effectively bridge nano-cracks. The common nanofibers include carbon nanotube and 
graphite nanoplatelets $[13,14]$. For example, the increase in graphite nanoplatelet from $0 \%$ to $0.1 \%$ enhanced the tensile strength of UHPC by $20 \%$ [13].

In order to use the UHPC in practical engineering, the model that describes the tensile stress-strain or stress-crack opening relationship should be developed. Yoo et al. [11] used inverse analysis to determine trilinear curves to describe the relationship between tensile stress and crack opening of UHPC. This trilinear curve includes an initial plateau and a softening branch with a kink point [11]. The model was successfully verified using experimental results of UHPC made with different fiber content and orientation. Lampropoulos et al. [15] established tensile stress-strain response using a trilinear curve consisting of a linear increase followed by a bilinear descending branch. The finite element model (FEM), considering this trilinear tensile stress-strain curve, can accurately predict the flexural load-deflection curves of UHPC made with different fiber lengths and contents [15].

The performance of the UHPC beam with reinforcing steel (R-UHPC) at the structural level has also been tested. Graybeal [16] reported that the use of UHPC with compressive strength of $190 \mathrm{MPa}$ can enable a 30\% decrease in the cross-section of the area of girders compared to conventional concrete with a compressive strength of $55 \mathrm{MPa}$. The failure pattern in flexural showed that closely spaced cracks can form in prestressed I-girders. Yang et al. [17] investigated the structural behavior of 14 UHPC beam specimens with rectangular cross-sections. The results showed that UHPC beams exhibited a post-cracking ductility in spite of the use of reinforcing steel. The incorporation of steel fibers was shown to decrease the demand for reinforcing steel [17].

The performance of the R-UHPC structure can be simulated by combining the FEM and predefined tensile stress-strain curve of UHPC $[13,18]$. For example, Maio et al. [13] predicted the flexural performance of the R-UHPC beam made with graphite nanoplatelet using the FEM. In the model, UHPC material was simulated using a solid element where a trilinear softening curve was employed to simulate the tensile behavior. Furthermore, the embedded truss model was used to simulate reinforcing steel. The results show that the tension-stiffening effect corresponding to the capability of concrete to sustain the tensile stress between adjacent main cracks can be correctly simulated [13]. However, it is relatively complicated and time-consuming to establish and calculate the FEM using solid elements. In the view of sustainability, it is important to seek a relatively simple simulation method to reduce the investing time and resources when accurate results can be secured.

The FEM model based on beam elements is commonly used in the design of reinforced concrete (RC) structures due to its ease of use. The inertia of bending moment is the key parameter to obtain accurate modeling results, especially for cracked RC structures. In $\mathrm{RC}$ flexural design, the contribution of tensile strength of concrete is ignored between consecutive flexural cracks. However, such calculation underestimates the stiffness of the cracked member since the tension-stiffening effect is ignored. Considering the tensile strength of non-cracked concrete can enhance the accuracy of deflection calculation of cracked RC beams.

Several modes have been proposed to calculate the stiffness of cracked RC beam elements. For example, the ACI 318 Building Code [19] uses an effective moment of inertia $\left(I_{e}\right)$ to compute the immediate deflection of cracked RC beams based on the ratio of cracking moment to moment of the applied load $\left(M_{c r} / M_{a}\right)$. The $I_{e}$ can be calculated using the inertia of the non-cracked section and cracked section (refer to $I_{n c}$ and $I_{c}$, respectively), cracking bending moment $\left(M_{c r}\right)$, and the bending moment induced by applied load $\left(M_{a}\right)$, as shown in Equation (1) [19]. However, this method does not take the effect of tension stiffening into consideration.

$$
I_{e}=\left(M_{c} / M_{a}\right)^{3} I_{n c}+\left[1-\left(M_{c} / M_{a}\right)^{3}\right] I_{c}
$$

The tension stiffening is determined by the bond strength between the concrete and the reinforcing steel. The CEB-FIP model code [20] proposes a simplified model that considers the tension stiffening of cracked RC beams. The bond strain between the reinforcing steel bar and concrete is assumed to be constant along half of the cracking spacing. Then the average curvature and deflection of the cracked beam are calculated. In general, one of the 
most important parameters affecting the deflection estimation is the active cross-section area $\left(A_{c t . e f}\right)$ under tension. Castel et al. [21] proposed a model to determine $A_{c t . e f}$ to predict the deflection of cracked RC beams under static loading. The predicted flexural loaddeflection response was validated using five beams made with different cross-sections and reinforcement layouts. The spreads between predicted and experimental results were less than 15\% [21]. The results in this study also show that neglecting the tensile stress of non-cracked concrete in the FEM model can lead to 50\% higher deflection compared to the experimental results [21]. Castel et al. [22] further developed the model by considering a linear strain distribution of the bond between the reinforcing steel and concrete to predict the load-deflection curves of cracked RC beams. The spreads between predicted and experimental results of five RC beams made with different strength levels of concrete and cross-sections were shown to be less than $10 \%$ [22]. This tension-stiffening effect was also important to estimate the effect of cycle loading on the loading-deflection curves of cracked $\mathrm{RC}$ beams where the spreads between predicted and experimental results were shown to be less than 15\% [23]. As discussed above, it is important to consider the tension-stiffening effect to predict the flexural loading-deflection response of the RC beam.

The effect of tension stiffening on the flexural behavior of R-UHPC beams is higher than that of RC beams due to the cracking-bridging effect of steel fiber [24-26]. For example, Ganesan et al. [25] reported that the increase in steel fiber contents from $0 \%$ to $1 \%$ extended the deflection-hardening behavior and increased the yield load from 40 to $49 \mathrm{kN}$. However, limited information is available to consider the tension-stiffening effect into the FEM model based on beam element to predict the load-deflection response of cracked R-UHPC beams.

This study aims to develop a model to calculate the average inertia of bending moment of cracked R-UHPC beams with the consideration of the tension-stiffening effect. The deflection of beams can be predicted using the proposed inertia of bending moment. The load-deflection relationships of tested beams were used to validate the developed model. This work contributed to the enhancement of prediction accuracy for the deflection of R-UHPC beams.

\section{Materials and Methods}

\subsection{UHPC Materials and Mixture Proportion}

The water-to-binder mass ratio was set at 0.20 . The binder incorporated $80 \%$ ordinary Portland cement and $20 \%$ silica fume (SF) by volume of the total binder. The chemical composition has been summarized in Table 1 . The average particle size and BET-specific surface area of the SF were $0.25 \mu \mathrm{m}$ and $18,000 \mathrm{~m}^{2} / \mathrm{kg}$, respectively. BET (Brunauer, Emmett, and Teller) is a method to determine the specific surface area of the particle using gas adsorption. The sand-to-binder volume ratio was set at 0.8 . The maximum size and specific gravity of the fine sand are 2 and $2.5 \mathrm{~mm}$, respectively. Figure 1 shows the granulometric curve for the fine sand.

Table 1. Chemical compositions of cement and silica fume (unit: \%).

\begin{tabular}{ccccccccc}
\hline & $\mathrm{SiO}_{2}$ & $\mathrm{Al}_{2} \mathrm{O}_{3}$ & $\mathrm{Fe}_{\mathbf{2}} \mathrm{O}_{3}$ & $\mathrm{CaO}$ & $\mathrm{MgO}$ & $\mathrm{SO}_{3}$ & $\mathrm{Na}_{2} \mathrm{O}_{\text {eq }}$ & $\mathbf{R}_{\mathbf{2}} \mathrm{O}$ \\
\hline Cement & 20.76 & 4.58 & 3.27 & 62.89 & 3.13 & 2.80 & 0.57 & - \\
\hline Silica fume & 93.90 & - & 0.59 & 1.85 & 0.27 & - & - & 1.03 \\
\hline
\end{tabular}




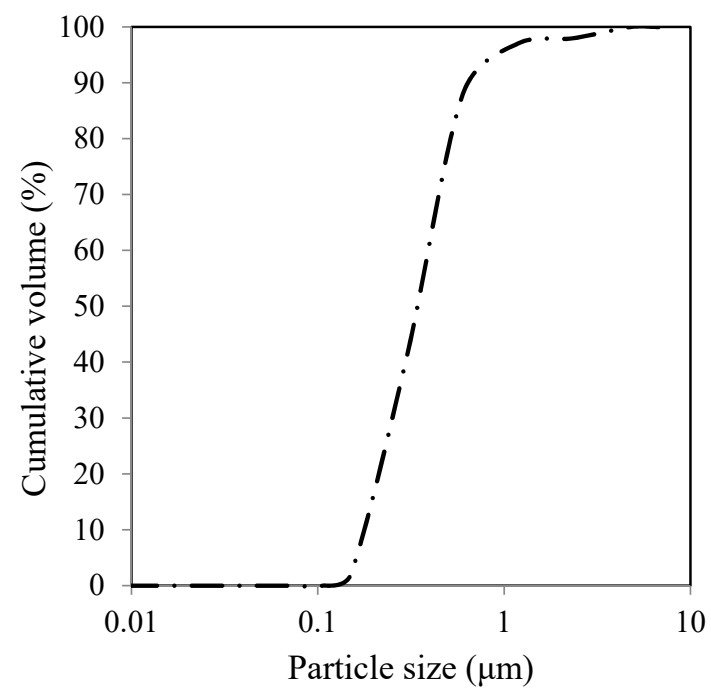

Figure 1. Size distribution of fine sand.

A polycarboxylate-based high-range-water reducer (HRWR) with $30 \%$ solid content was used to secure a slump flow of $200 \mathrm{~mm}$ for the UHPC prepared with fibers. The slump flow was determined on the UHPC sample cast in the mini-slump cone in one layer without any consolidation. The upper and lower inner diameter of the mini-slump cone are 70 and $100 \mathrm{~mm}$, respectively, and the height is $50 \mathrm{~mm}$. Straight steel microfibers with a length of $13 \mathrm{~mm}$ and a diameter of $0.2 \mathrm{~mm}$ were incorporated. The tensile strength and elastic modulus of the fibers are $190 \mathrm{MPa}$ and $203 \mathrm{GPa}$, respectively. The fiber volume was set at $2 \%$. The fiber content was determined based on the work of [27], where the increase in fiber content from $0.5 \%$ to $2 \%$ enhanced the flexural strength and toughness of UHPC by $25 \%$ and $105 \%$, respectively. Further increase in fiber content from $2 \%$ to $2.5 \%$ had a limited effect on the flexural strength and toughness due to the high risk of fiber agglomeration. The mixture proportions of UHPC are listed in Table 2.

Table 2. Mixture proportions of UHPC $\left(\mathrm{kg} / \mathrm{m}^{3}\right)$.

\begin{tabular}{ccccccc}
\hline Material & Cement & SF & Sand & Water & HRWR & Fiber \\
\hline UHPC & 1010 & 145 & 800 & 235 & 34 & 150 \\
\hline
\end{tabular}

\subsection{Mixing, Casting, and Curing}

A high-shear mixer with a capacity of $200 \mathrm{~L}$ was used to prepare the UHPC. The mixing procedure was as follows: (1) mixing all sand for $1 \mathrm{~min}$ at $2 \mathrm{rps}$; (2) adding cementitious materials and mixing for $2 \mathrm{~min}$ at $2 \mathrm{rps}$; (3) adding the water and HRWR and mixing $10 \mathrm{~min}$ at $6 \mathrm{rps}$; (4) gradually adding fibers and mixing $4 \mathrm{~min}$ at $6 \mathrm{rps}$. In total, three batches of $140 \mathrm{~L}$ were prepared for casting three reinforced concrete beams and specimens for testing the mechanical performance of materials.

Three UHPC beams and molded specimens were consolidated using internal vibration. Then, they were covered with wet burlap and plastic sheet for $24 \mathrm{~h}$. Following demolding, they were subjected to moist curing at $23 \pm 2{ }^{\circ} \mathrm{C}$ until the time of testing. It should be mentioned that this study did not use any special method to promote fiber alignment. The fibers were randomly oriented in the specimens.

The compressive strength was tested in accordance with ASTM C 109 using three $50 \mathrm{~mm}$ cubes. The splitting tensile strength was determined based on ASTM C 496 using three $150 \times 300 \mathrm{~mm}$ cylinders. The elastic modulus was obtained by determining the slope of the stress-strain curves between the $10 \%$ and $30 \%$ compressive strength [28]. The mean values and the coefficient of variation (C.O.V.) of compressive and splitting tensile strengths and elastic modulus of the UHPC prepared for each of the three batches used 
to cast reinforced concrete beams are summarized in Table 3. As shown in Table 3, the C.O.V. of the mechanical properties ranged between $3 \%$ and $7 \%$. The compressive and tensile strengths of the investigated UHPC mixture were approximately 120 and $10 \mathrm{MPa}$, respectively. The elastic modulus was approximately $45 \mathrm{GPa}$. These mechanical properties satisfied the lowest strength level of UHPC based on ASTM C1856.

Table 3. The $28 \mathrm{~d}$ mechanical properties of UHPC mixture.

\begin{tabular}{ccccccc}
\hline Material & Batch 1 & C.O.V & Batch 2 & C.O.V & Batch 3 & C.O.V \\
\hline Compressive strength (MPa) & 121.9 & $3 \%$ & 124.2 & $4 \%$ & 114.3 & $6 \%$ \\
Splitting tensile strength (MPa) & 9.8 & $7 \%$ & 10.9 & $3 \%$ & 10.1 & $5 \%$ \\
Modulus of elasticity(GPa) & 46.6 & $5 \%$ & 45.4 & $4 \%$ & 44.8 & $5 \%$ \\
\hline
\end{tabular}

\subsection{Flexural Beam Specimens}

The T-beams prepared by the same UHPC mixture were used to validate the model proposed in Section 3.4. These investigated beams had a similar reinforcement layout and geometry of cross-section compared to beam specimens tested by Aaleti et al. [29], where no stirrups were used. The three tested beams were cast using three different batches. As shown in Figure 2, the beams measure $3000 \mathrm{~mm}$ in length and $2700 \mathrm{~mm}$ in span. The dimensions and reinforcing steel layout of the $\mathrm{T}$ section are also shown in Figure 2. Two reinforcing steel with a yield stress of $400 \mathrm{MPa}$ and a diameter of $22 \mathrm{~mm}$ were laid out in the flange and rib, respectively. The distances from the reinforcing steel in the flange and rib to the top of the section are 55 and $155 \mathrm{~mm}$, respectively.

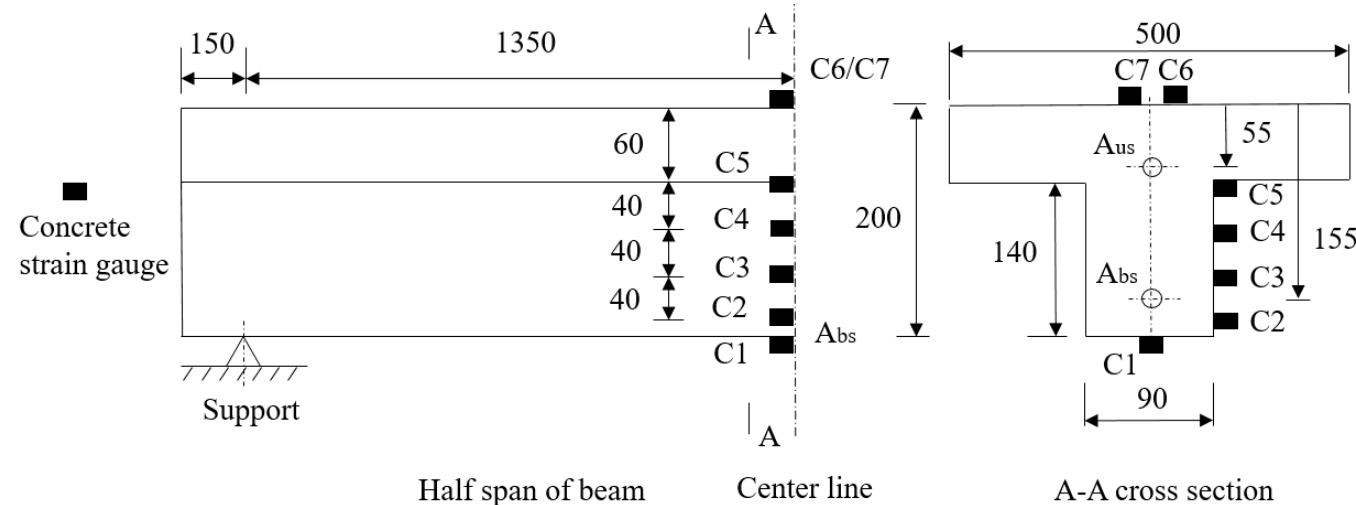

Figure 2. Beam specimen dimensions and cross-section (mm).

\subsection{Test Setup and Instrumentation}

Figure 3a shows that the four-point loading was applied using a hydraulic actuator. A loading distribution girder was installed to distribute the load from the actuator to the beam. The distance between the locations of the applied load was $1350 \mathrm{~mm}$. The loading location of the test is shown in Figures $3 \mathrm{a}$ and 4 . The beam test was conducted by the load control with a load step of $10 \mathrm{kN}$. The test was terminated when the beam reached the ultimate state.

For each T-beam test, seven concrete strain gauges (C1 to C7) are located on the top, side, and bottom of the beam at the mid span, respectively, as shown in Figure 2. The strain gauges on the side of the beam are also shown in Figure 3b. The strain gauges were $60 \mathrm{~mm}$ in length. The strain variation of the rebar at the mid span of the rib was monitored using strain gauges measuring $5 \mathrm{~mm}$ in length. In addition to the strain gauge that was attached to the surface of concrete, eight displacement gauges were placed at mid span, quarter span, and support location to monitor the deflection of the beam during loading. 


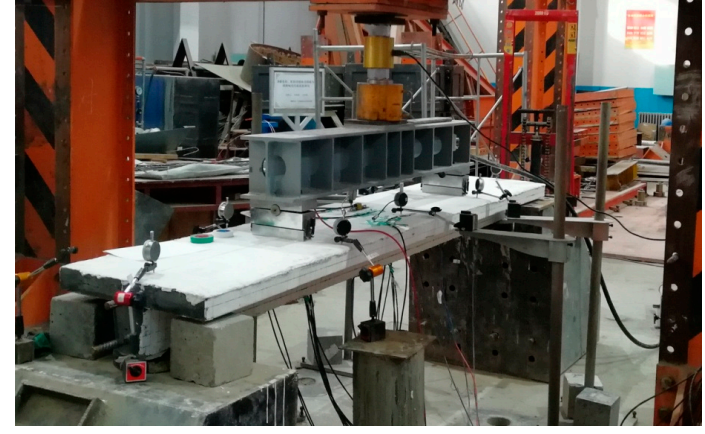

(a)

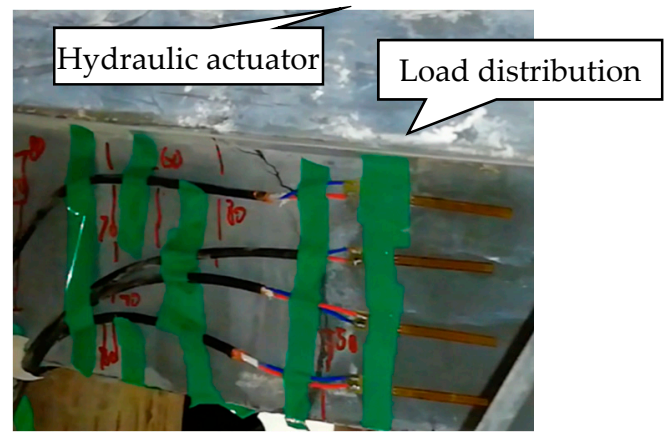

(b)

Figure 3. Experimental photo of test setup: (a) LVDT and (b) concrete strain gauges.

Top surface of beam

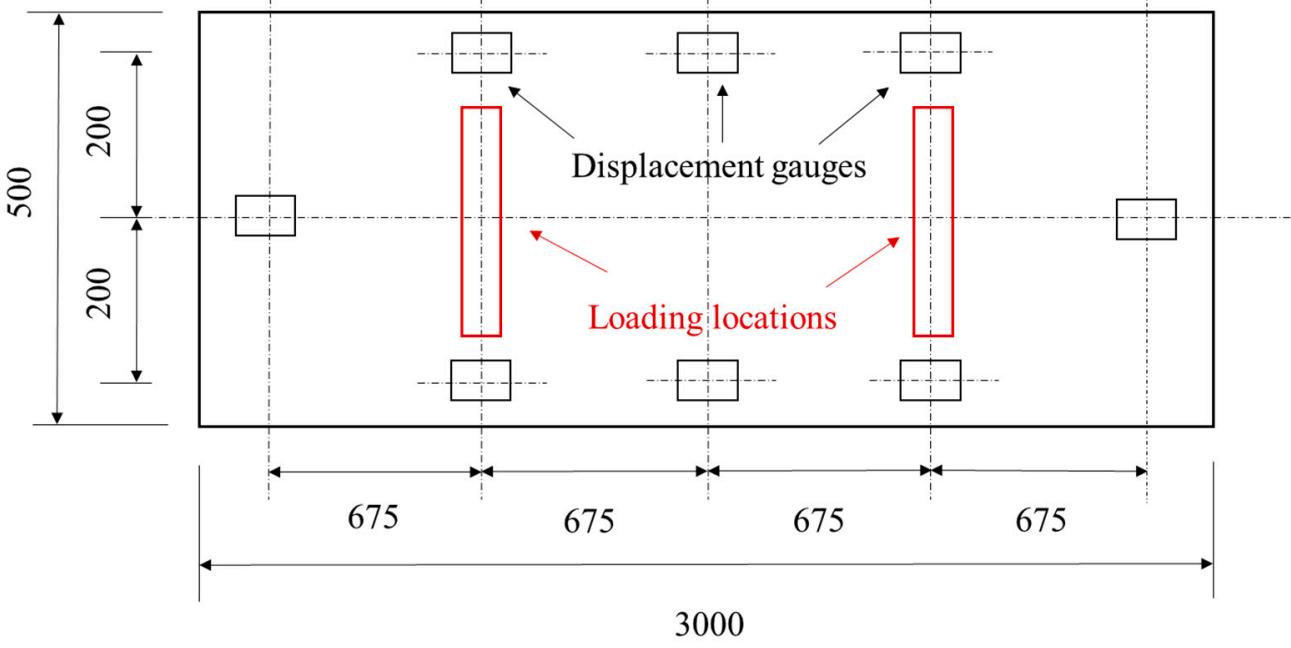

Figure 4. Top view of the location of applied loading and displacement gauges (mm).

\section{Experimental Results and Discussion}

\subsection{Cracking and Failure Modes}

Figure 5 shows the cracking patterns of the three UHPC beams at the failure stage. The numbers on the beams correspond to the load stages when cracks occurred. Several flexural cracks measuring $0.02-0.04 \mathrm{~mm}$ in width were initiated in the pure bending moment region when the applied load exceeded approximately $30 \mathrm{kN}$. The further increase in applied loading from 30 to $100 \mathrm{kN}$ led to many new micro cracks around the pure bending region but slowed the increase in crack width and length. The maximum crack width was $0.5 \mathrm{~mm}$ when the applied loading reached approximately $100 \mathrm{kN}$. As the loading continually increased, three or four cracks transformed into the main cracks. They rapidly increased from 0.5 to $6-10 \mathrm{~mm}$ in width and propagated into the flange of the beam, as shown in Figure 6. The crack numbers and crack width of other cracks had a limited change in this stage. In general, R-UHPC beam specimens exhibited 3-4 main cracks and 40-55 tiny cracks at the failure stage. The width of the main crack was approximately $10 \mathrm{~mm}$, and fibers were shown to be pulled out from the UHPC matrix. The width of tiny cracks was less than $2 \mathrm{~mm}$. 


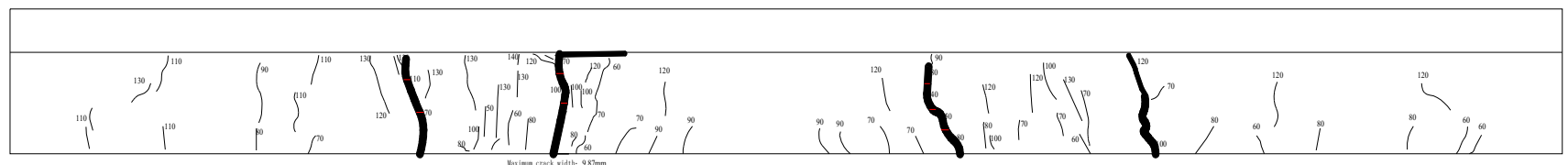

(a)

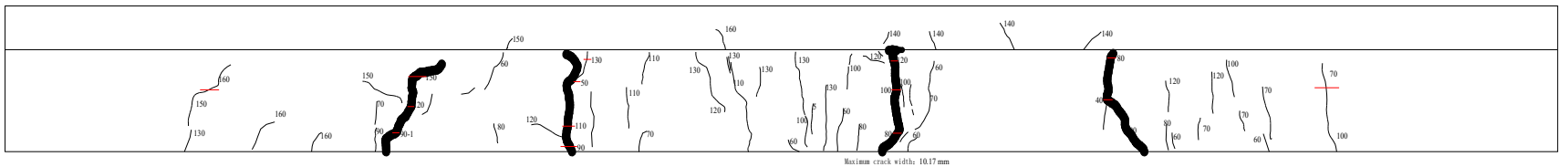

(b)

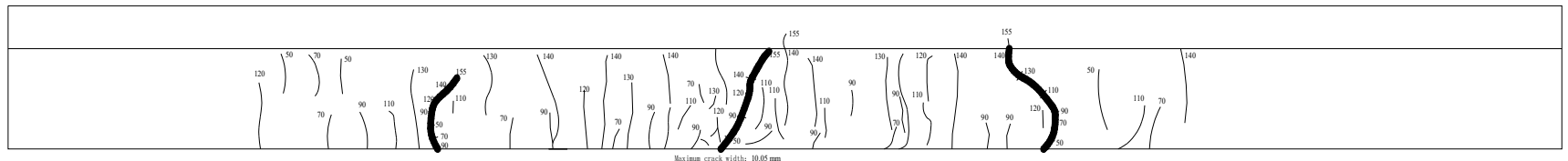

(c)

Figure 5. Cracking patterns of three UHPC beams: (a) beam 1; (b) beam 2; and (c) beam 3.

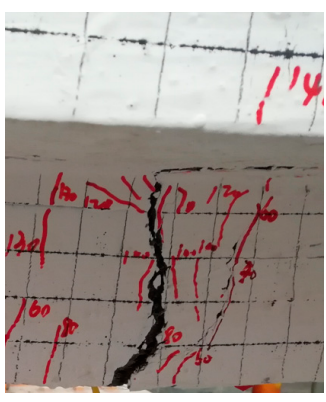

(a)

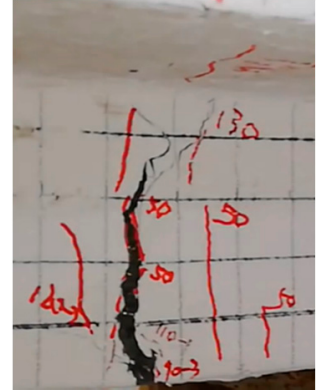

(b)

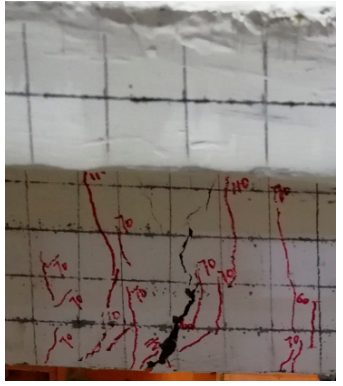

(c)

Figure 6. Experimental photos of one of the primary cracks of beams (a) 1 ; (b) 2; and (c) 3 .

The correlation between load and deflection was linear before the formation of cracks. When the load increased from 20 to $90 \mathrm{kN}$, the load-deflection curves were nonlinear. The slope of the curves during this stage was lower compared to that of the initial loading between 0 and $20 \mathrm{kN}$. This can be attributed to the formation and propagation of micro cracks. The cracks can be clearly observed when the load exceeds $50 \mathrm{kN}$, which corresponds to $35 \%$ of the ultimate flexural loading. The increase in loading led to the formation of a higher degree of cracking, resulting in a decrease in crack spacing. The variation of crack width was limited when the applied load was lower than $100 \mathrm{kN}$. Beyond $100 \mathrm{kN}$, fibers in some cross-sections were gradually pulled out, resulting in the formation of major cracks. The ultimate state was attained when the load reached approximately 130-140 kN. Furthermore, the deflection rapidly increased with a limited increase in applied load, as shown in Figure 7. The loading capacity of beam 2 at this state was approximately $10 \%$ higher than that of beam 1 and 3 when the deflection was approximately equal to $25 \mathrm{~mm}$. This slightly higher loading capacity can be considered experimental error. The concrete flange at mid span exhibited some crushing failure. During the loading process, no obvious shear cracks were observed for the tested beams. 


\subsection{Load-Deflection Relationships}

The relationship between load and mid-span deflection is shown in Figure 7. It can be observed that the load-deflection curves of the three beams were quite similar.

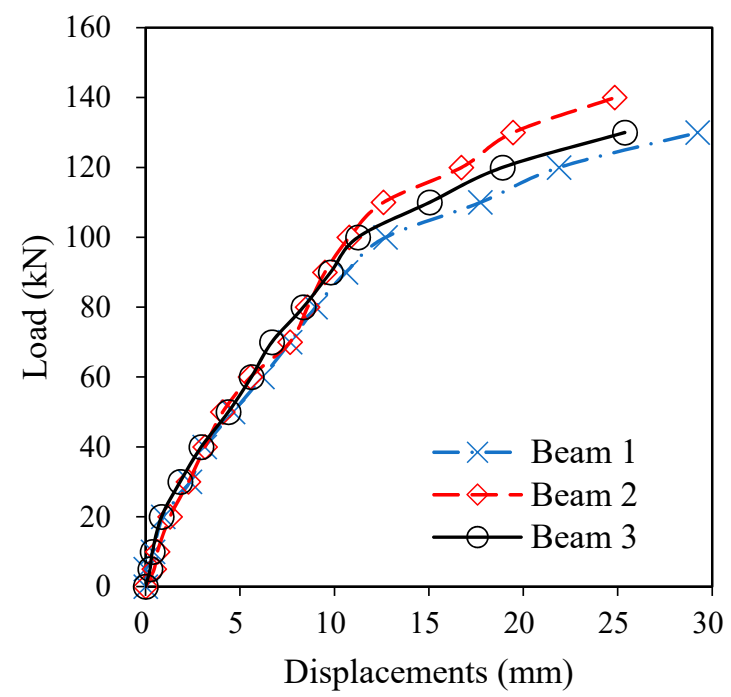

Figure 7. Load-deflection relationships for investigated beams.

As shown in Figure 8, the variations of the deflection of beam 1 were determined from LVDTs positioned at different locations along the span of the beam. As expected, the mid-span deflection was higher than that at the quarter span and support locations. The amplification of the displacement increased with the increase in load. For example, the increase in load from 0 to $20 \mathrm{kN}$ and then from 110 to $130 \mathrm{kN}$ led to an increase in deflection of 2 and then $10 \mathrm{~mm}$, respectively. The deflections of the beam on the left and right sides of the beam were not symmetrical. This can be attributed to the heterogeneity of the UHPC material. A similar phenomenon was observed in beams 2 and 3 .

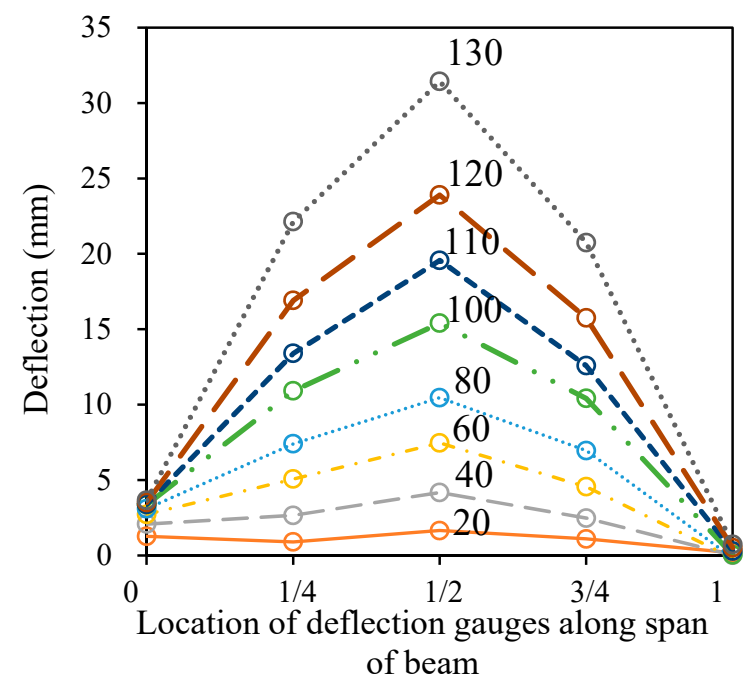

Figure 8. Load-deflection relationship along the beam.

\subsection{Load-Strain Relationships}

The typical load-strain relationships of beam 1 are shown in Figure 9. The positive and negative strains represent tensile and compressive strains, respectively. The positive strains determined at strain gauge of $\mathrm{C} 6$ and $\mathrm{C} 7$ indicate that the top of the beam was under compression, while negative strains of the $\mathrm{C} 1$ to $\mathrm{C} 4$ strain gauges indicate that the tensile strains of UHPC developed in the rib and bottom of the beam. The rebar in the rib 
developed tensile strain, as shown in the curve of S1. A similar phenomenon was observed in beams 2 and 3 .

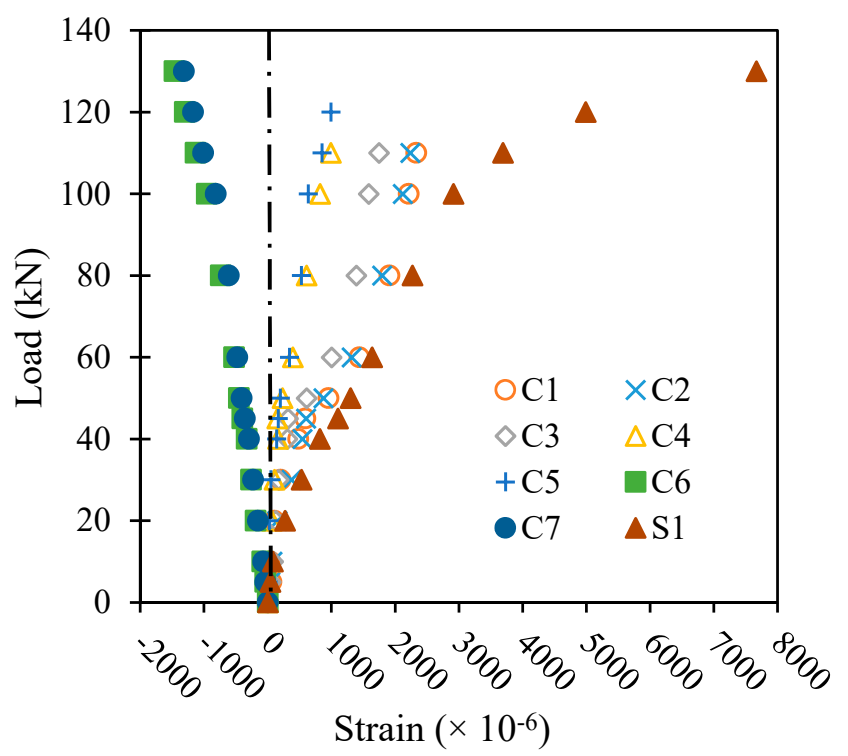

Figure 9. Load-strain relationship of beam 1.

The increase in load resulted in an increase in compressive strain the top of the beam, as shown in the C6 and C7 curves determined from the strain gauges located at the top of the beams. The C5 strain gauges located at the interface between flange and rib indicated that the strain of $\mathrm{C} 5$ was close to zero at the load level of 0 to $20 \mathrm{kN}$. This indicated that the neural axis is close to the flange before cracking. As the load increased, the tensile strain at C5 appeared gradually since the neutral axis moved upward. Furthermore, the tensile strains determined of C1 and C2 strain gauges located at the bottom of beams did not show any abrupt change when the crack initiated, which was different from the behavior of tensile strain in conventional reinforced concrete. Such behavior was in suitable agreement with the cracking pattern shown in Figure 10. This may be attributed to the effect of the fibers on crack bridging. Beyond $120 \mathrm{kN}$, the concrete strain gauge in the tensile zone failed to record data due to the formation of wide cracks. The rebar in the tension zone yielded during this stage of loading.

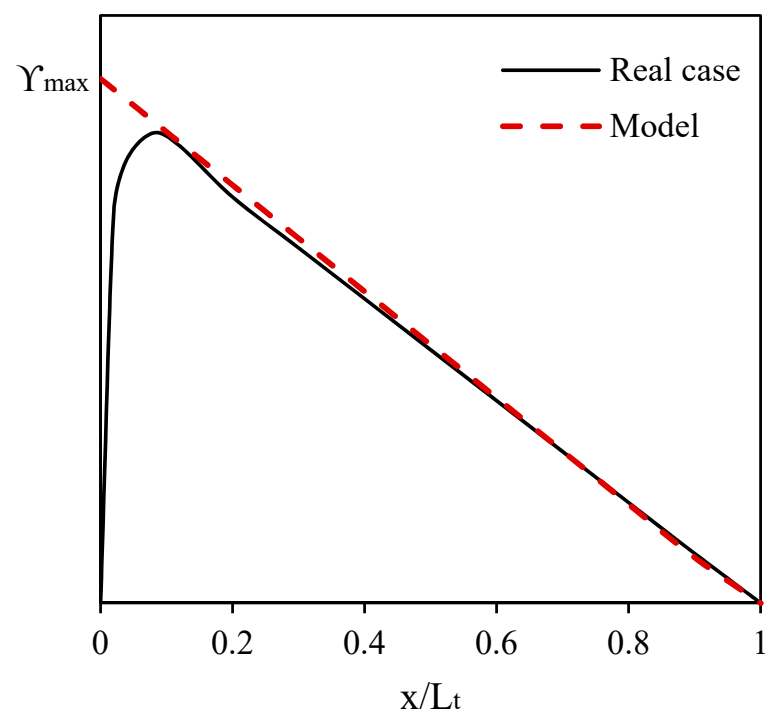

Figure 10. Linear bond strain distribution along the transfer length. 


\subsection{Computational Formula of Average Inertia of Bending Moment of Cracked Beams}

\subsubsection{Strain Distribution of Reinforcing Steel and UHPC along Transfer Length}

Figure 10 shows the distribution of bond strain between UHPC and reinforcing steel along the transfer length. The transfer length $\left(L_{t}\right)$ is defined as half of the average distance between two adjacent cracks. In other words, it corresponds to the length between the place where the UHPC strain is equal to that of reinforcing steel at the crack location. The bond strain between cracked UHPC and reinforcing steel is assumed to be zero at the cracked cross-section. The bond between non-cracked UHPC and reinforcing steel can redevelop tensile stress from reinforcing steel to UHPC. Finally, the strain of UHPC and reinforcing steel can equal each other. The bond is assumed to be linear along the transfer length, as shown in Figure 10.

Figure 11 shows that the variations of the strain of the UHPC and reinforcing steel along the transfer length, which can be derived by integrating and determining the boundary conditions based on the assumed bond strain. The calculated equations are Equations (2) and (3) [21,30].

$$
\begin{gathered}
\mathcal{E}_{s}(x)=(1-g(x)) \varepsilon_{s}+g(x) \varepsilon_{s . m i n} \\
g(x)=2\left(\frac{x}{L_{t}}\right)-\left(\frac{x}{L_{t}}\right)^{2}
\end{gathered}
$$

where $g(x)$ is the distribution function, $\varepsilon_{S}$ is the strain of reinforcing steel at the cracked section, and $\varepsilon_{s . \min }$ is the strain of reinforcing steel at the location where the $x / L_{t}=1$.

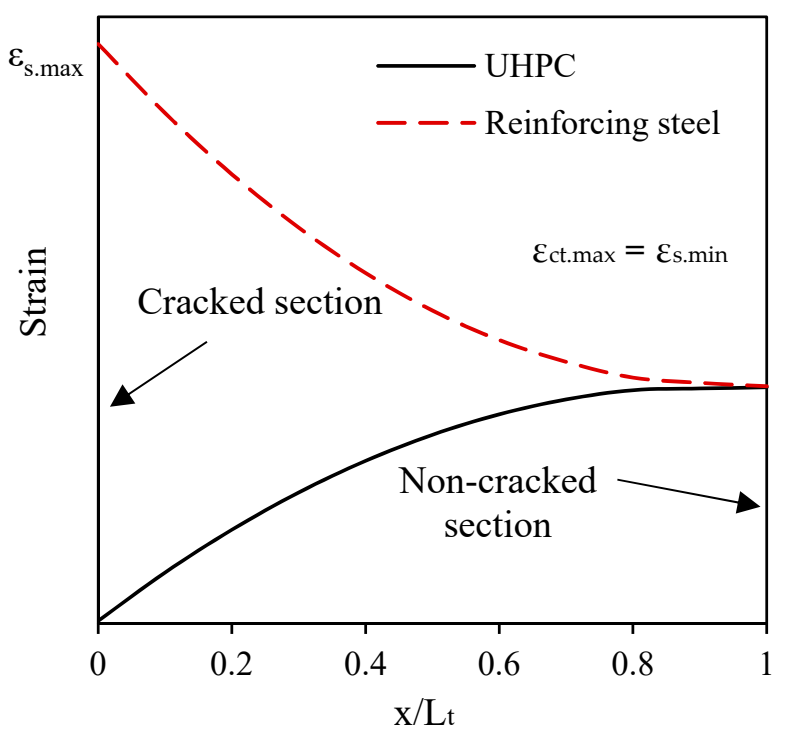

Figure 11. Nonlinear strain distribution of reinforcing steel and UHPC along the transfer length.

\subsubsection{Strain and Stress Distributions along Non-cracked Cross-section of T Beam}

The location of the neutral axis varies for different cracked and uncracked sections of cracked beams. In general, the location of the neutral axis does not change in UHPC with narrow cracks compared to that before cracking. However, as the crack amplitude increases (starting at crack width of $2 \mathrm{~mm}$ ), the position of the neutral axis moves toward the top of the beam. The strain and stress distributions along the non-cracked cross-section are shown in Figure 12. After cracking, the location of the neutral axis of the cross-section of concrete with no cracks or narrow cracks can be assumed to be the same as that of concrete before cracking. The crack opening and propagation can lead to a relaxation of tensile stress in concrete $[21,31]$. This phenomenon concentrates mainly on the section below the reinforcing steel. The tensile stress of the UHPC in that section of the rib is simplified to be equal to that at the level of reinforcing steel. 


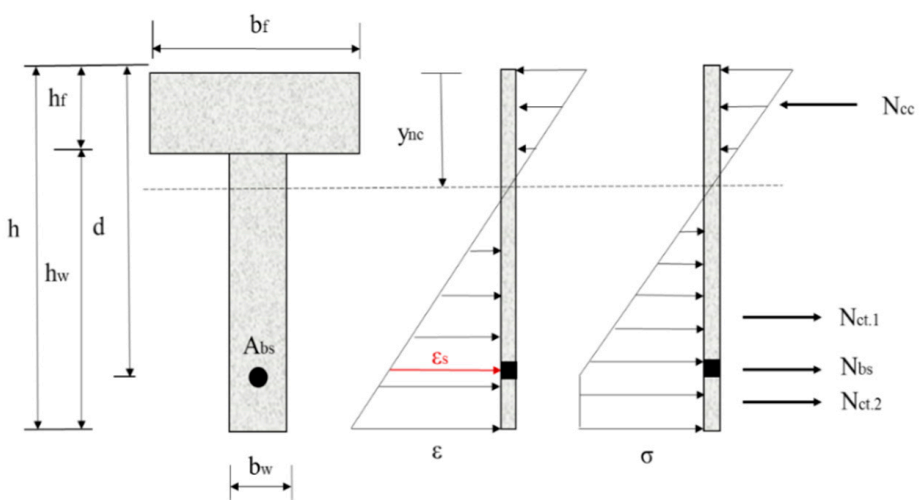

Figure 12. Strain and stress distribution along the non-cracked cross-section.

Based on the above assumptions, the balance of axial load and bending moment in the non-cracked section are as follows:

$$
\begin{gathered}
N_{c c}=N_{c t .1}+N_{c t .2}+N_{b s} \\
M=N_{c t .1}\left(\frac{2 d}{3}+\frac{y_{n c}}{3}-z_{n c}\right)+N_{c t .2}\left(\frac{h+d}{2}-z_{n c}\right)+N_{b s}\left(d-z_{n c}\right)
\end{gathered}
$$

where $N_{c c}$ is the axial load of the UHPC in the compression zone; $N_{c t}$ is the axial load of UHPC in the tensile zone; and $N_{b s}$ is the axial load of the reinforcing steel in the rib. $z_{n c}$ refers to the distance between the $N_{c c}$ and top of the cross-section. Those terms can be calculated as follows:

$$
\left\{\begin{array}{l}
N_{c c}=\frac{0.5 E_{c} \varepsilon_{s} b_{f} h_{f}\left(2 y_{n c}-h_{f}\right)}{d-y_{n c}}+\frac{0.5 E_{c} \varepsilon_{s} b_{w}\left(y_{n c}-h_{f}\right)^{2}}{d-y_{n c}} \\
N_{c t .1}=0.5 E_{c} \varepsilon_{s} b_{w}\left(d-y_{n c}\right) \\
N_{c t .2}=E_{c} \varepsilon_{s} b_{w}(h-d) \\
N_{b s}=E_{s} \varepsilon_{s} A_{b s}
\end{array}\right.
$$

\subsubsection{Strain and Stress Distribution along Cracked Cross-section of T Beam}

Yang et al. [32] reported that the stress distribution along the cross-section of UHPC beams can be estimated by the stress-strain relationship for concrete. Graybeal [33] reported that the tensile response of cracked UHPC under service load can be regarded as an elasticperfectly plastic response with a constant stress capacity. Such stress is assumed the same as the initial tensile cracking stress. The strain and stress distributions along the cracked cross-section are shown in Figure 13, where the $y_{c}$ is the distance between the neutral axis and the top of the beam. It should be noted that this assumption is not appropriate for UHPC beams loaded at the ultimate stage, given the fiber pullout.

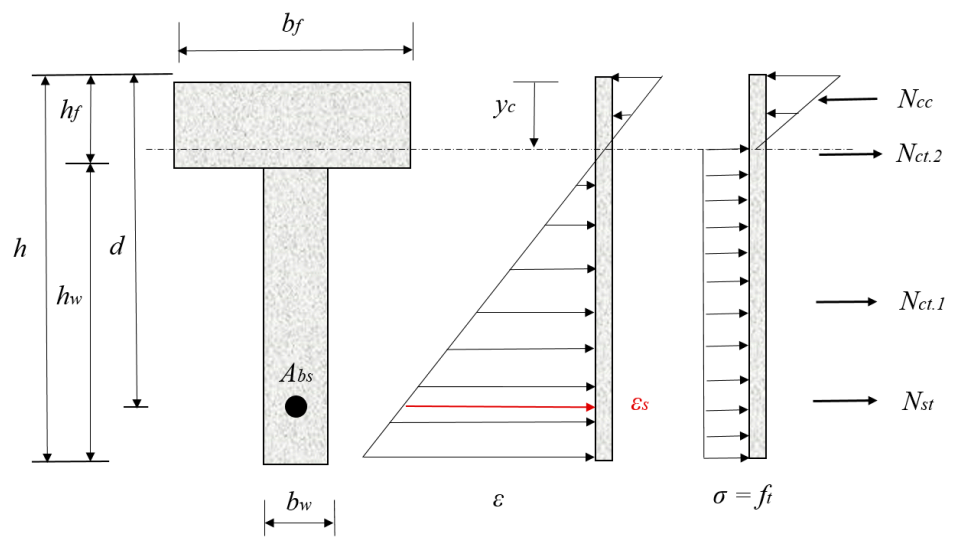

Figure 13. Strain and stress distribution along the cracked cross-section. 
Similar to the non-cracked section, the balance of axial load and bending moment in the cracked section can be deduced as follow:

For $0<y_{c}<h_{f}$ :

$$
\begin{gathered}
N_{c c}^{1}=N_{c t .1}^{1}+N_{c t .2}^{1}+N_{b s}^{1} \\
M=N_{b s}^{1}\left(d-z_{c}\right)+N_{c t .1}^{1}\left(\frac{h_{w}}{2}+h_{f}-\frac{y_{c}}{3}\right)+N_{c t .2}^{1}\left(\frac{h_{f}}{2}+\frac{y_{c}}{6}\right)
\end{gathered}
$$

For $y_{c}>h_{f}$ :

$$
\begin{gathered}
N_{c c}{ }^{2}=N_{c t}{ }^{2}+N_{b s}^{2} \\
M=N_{b s}{ }^{2}\left(d-z_{c}\right)+N_{c t}^{2}\left(\frac{h}{2}+\frac{y_{c}}{2}-z_{c}\right)
\end{gathered}
$$

where $N_{c c}$ is the axial load of the UHPC in the compression zone; $N_{c t .1}$ and $N_{c t .2}$ are the axial load of UHPC in the flange and rib of the tensile zone, respectively; $N_{b s}$ is the axial load of the reinforcing steel in the rib. $z_{c}$ refers to the distance between the $N_{c c}$ and top of the cross-section. Other terms can be calculated as follows:

$$
\left\{\begin{array}{l}
N_{c c}^{1}=\frac{0.5 E_{c} \varepsilon_{s} b_{f} y_{c}^{2}}{d_{1}-y_{c}} \\
N_{c c}^{2}=\frac{0.5 E_{c} \varepsilon_{s} b_{f} h_{f}\left(2 y_{c}-h_{f}\right)}{d-y_{c}}+\frac{0.5 E_{c} \varepsilon_{s} b_{w}\left(y_{c}-h_{f}\right)^{2}}{d-y_{c}} \\
N_{c t .1}^{1}=f_{t} h_{w} b_{w} \\
N_{c t .2}^{1}=f_{c}\left(h_{f}-y_{c}\right) b_{f} \\
N_{c t}^{1}=N_{c t .1}^{1}+N_{c t .2}^{1} \\
N_{c t}^{2}=f_{t}\left(h-y_{c}\right) b_{w} \\
N_{b s}=E_{s} \varepsilon_{s} A_{b s}
\end{array}\right.
$$

where $E_{c}$ is the elastic modulus of UHPC; $E_{S}$ is the elastic modulus of reinforcing steel; $\varepsilon_{S}$ is the strain of reinforcing steel; $f_{t}$ is the tensile strength of UHPC; $A_{b s}$ is the area of reinforcing steel; $h$ is the total depth of cross-section; $d$ is the effective depth of cross-section; $h_{f}$ and $h_{w}$ are the depth of flange and rib of cross-section, respectively; and $b_{f}$ and $b_{w}$ are the width of flange and rib of cross-section, respectively.

\subsubsection{Calculation of $\varepsilon_{\mathrm{s} . \mathrm{min}}$ and $\varepsilon_{\text {UHPC.max }}$ in Non-cracked Section of T-beam}

All cross-sections are assumed to be under the same bending moment. Equation (5) can be combined with Equations (8) and (10) based on the different locations of the neutral axis, as shown in Equations (12) and (13).

For $0<y_{c}<h_{f}$ :

$$
\begin{aligned}
N_{c t .1}\left(\frac{2 d}{3}+\frac{y_{n c}}{3}-z_{n c}\right) & +N_{c t .2}\left(\frac{h+d}{2}-z_{n c}\right)+N_{b s}\left(d-z_{n c}\right) \\
& =N_{b s}^{1}\left(d-\frac{y_{c}}{3}\right)+N_{c t .1} 1\left(\frac{h_{w}}{2}+h_{f}-\frac{y_{c}}{3}\right)+N_{c t .2} 1\left(\frac{h_{f}}{2}+\frac{y_{c}}{6}\right)
\end{aligned}
$$

For $h_{f}<y_{c}<y_{n c}$ :

$$
\begin{aligned}
N_{c t .1}\left(\frac{2 d}{3}+\frac{y_{n c}}{3}-z_{n c}\right) & +N_{c t .2}\left(\frac{h+d}{2}-z_{n c}\right)+N_{b s}\left(d-z_{n c}\right) \\
& =N_{b s}{ }^{2}\left(d-z_{c}\right)+N_{c t}{ }^{2}\left(\frac{h}{2}+\frac{y_{c}}{2}-z_{c}\right)
\end{aligned}
$$

As $\varepsilon_{s . \text { min }}=\varepsilon_{c t \text { max }}$ in the non-cracked section $\left(x=L_{t}\right), \varepsilon_{s . \text { min }}$ and $\varepsilon_{c t \text { max }}$ are shown in Equation (14).

$$
\varepsilon_{\text {s.min }}=\varepsilon_{c t . \max }=\frac{\alpha \varepsilon_{s} c_{1}+f_{t} c_{2}}{c_{3}}
$$

where $\alpha$ is the ratio between $E_{s}$ and $E_{c}$. The $c_{1}, c_{2}$, and $c_{3}$ terms are coefficients that are expressed as below for different locations of the neutral axis: 


$$
\begin{aligned}
& \text { For } 0<y_{c}<h_{f}: \\
& \left\{\begin{array}{l}
c_{1}=E_{s} A_{b s}\left(d-z_{c}\right) \\
c_{2}=h_{w w} b_{w}\left(\frac{h_{w}}{2}+h_{f}-\frac{y_{c}}{3}\right)+b_{f}\left(h_{f}-y_{c}\right)\left(\frac{h_{f}}{2}+\frac{y_{c}}{6}\right) \\
c_{3}=E_{c}\left[\frac{b_{w w}}{6}\left(3 h^{2}-\left(d^{2}+y_{n c}^{2}+d y_{n c}\right)+3 z_{n c}\left(d+y_{n c}-2 h\right)\right)+n A_{b s}\left(d-z_{n c}\right)\right]
\end{array}\right.
\end{aligned}
$$

For $h_{f}<y_{c}<y_{n c}$ :

$$
\left\{\begin{array}{l}
c_{1}=E_{s} A_{b s}\left(d-z_{c}\right) \\
c_{2}=b_{w}\left(h-y_{c}\right)\left(\frac{h}{2}+\frac{y_{c}}{2}-z_{c}\right) \\
c_{3}=E_{c}\left[\frac{b_{w}}{6}\left(3 h^{2}-\left(d^{2}+y_{n c}^{2}+d y_{n c}\right)+3 z_{n c}\left(d+y_{n c}-2 h\right)\right)+n A_{b s}\left(d-z_{n c}\right)\right]
\end{array}\right.
$$

3.4.5. Calculation of the Average Inertia of Bending Moment of Cracked R-UHPC Beams

According to the simplified approach proposed by Francois [34], the distribution of the neutral axis along the transfer length can be assumed to be linear, as shown in Figure 14.

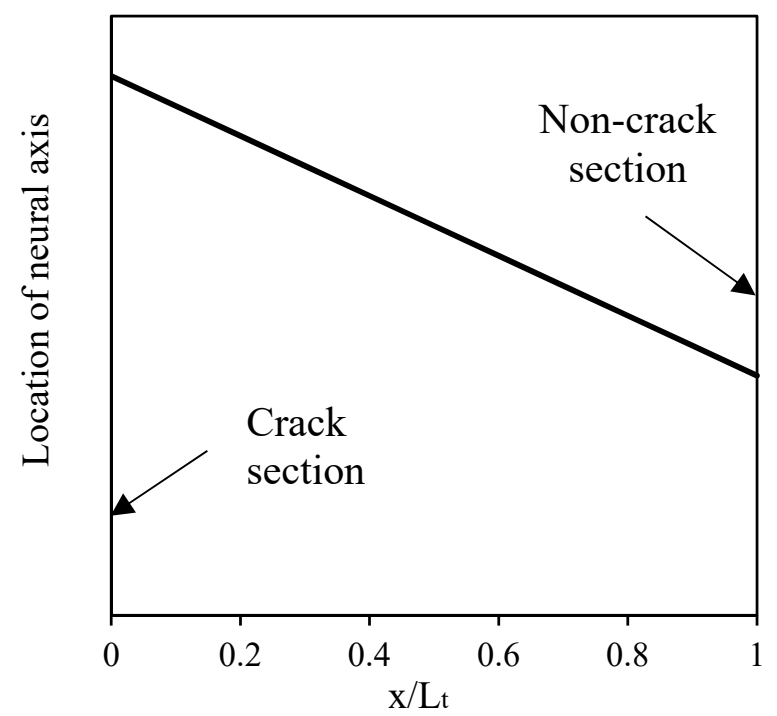

Figure 14. Linear distribution of the neutral axis along the transfer length.

The location of the average neutral axis along the transfer length can be expressed as follows:

$$
y_{a}=\frac{y_{c}+y_{n c}}{2}
$$

For conventional concrete, the number of cracks will increase with the increase in load. No new cracks will form when the half of cracking spacing is shorter than the transfer length. Finally, some cracks become wider in the following increase in loading. Murray et al. [35] reported that the ratio of average cracking spacing to transfer length was approximately 1.5. For UHPC beams with low fiber contents and without any reinforcing steel, only one main crack occurred under four-point bending loading [36]. Huang and Teng $[37,38]$ used a specific casting method to improve the fiber orientation and corresponding flexural performance of UHPC beams with $2 \%$ steel fibers and without any reinforcing steel. The results showed that there was only one main crack on UHPC with improved fiber orientation. Based on the above literature, the influence of steel fibers on the spacing of primary cracks of UHPC without any reinforcing steel is limited when the fiber content is low. Furthermore, the steel fibers have limited influence on the transfer length between the UHPC matrix and reinforcing steel, given its short length and discontinuity. Therefore, the ratio of the transfer length to cracking spacing of R-UHPC is assumed to be the same 
as that of the RC. Since the calculations of the model are based on half crack spacing, the average of steel strain $\left(\varepsilon_{s a}\right)$ along the half crack spacing can be calculated as follows:

$$
\left(0.75 L_{t}\right) \varepsilon_{s a}=\int_{0}^{0.75 L_{t}} \varepsilon_{s}(x) d x
$$

The average steel strain can be deduced by using Equations (2), (3), and (18), as follow:

$$
\varepsilon_{s a}=\left(1-C_{H}\right) \varepsilon_{s . \min }+C_{H} \varepsilon_{s . m a x}
$$

where $C_{H}$ is a coefficient related to the distribution function, $C_{H}=\frac{\int_{0}^{L_{t}} g(x) d x}{L_{t}}=0.6$.

The non-cracked and cracked sections were assumed to be subjected to the same bending moment. The relationship of the average curvature and curvature of the cracked section can then be expressed as:

$$
E_{c} I_{a} \varnothing_{a}=E_{c} I_{c} \varnothing_{c}
$$

where $\Phi_{a}$ is the average curvature of the cracked part of the beam, $I_{a}$ is the average inertia of bending moment of part of the cracked beam, $\Phi_{c}$ is the curvature in the cracked section, and $I_{\mathcal{C}}$ is the inertia of bending moment of the cracked cross-section of conventional concrete.

The strain distribution along the UHPC is assumed to be linear after cracking, as shown in Figure 5. The $\Phi_{a}$ and $\Phi_{c}$ terms can then be written as:

$$
\begin{aligned}
& \varnothing_{c}=\frac{\varepsilon_{s . m a x}}{\left(d_{1}-y_{c}\right)} \\
& \varnothing_{a}=\frac{\varepsilon_{s a}}{\left(d_{1}-y_{a}\right)}
\end{aligned}
$$

The average inertia of bending moment of part of the cracked beam can be calculated by using Equations (20)-(22), as follows:

$$
I_{a}=\frac{\left(d-y_{a}\right) \varepsilon_{s . m a x}}{\left(d-y_{c}\right) \varepsilon_{s a}} I_{c}
$$

Finally, $y_{a}$ and $\varepsilon_{s a}$ are given by Equations (17) and (19), respectively. The value of $I_{a}$ can be deduced from the location of reinforcing steel, the neutral axis of the cracked and non-cracked sections, and the strain of the UHPC and reinforcing steel at the non-cracked section, as shown in Equation (24). It should be mentioned that Equation (24) can be used to calculate the stiffness of beams with different cross-sectional configurations. The $c_{1}, c_{2}$, and $c_{3}$ parameters vary with the change of cross-sectional configuration. It should be mentioned that the proposed $I_{a}$ can only predict the load-deflection response of the R-UHPC beam before the yield of reinforcing steel.

$$
I_{a}=\frac{2 d-y_{c}-y_{n c}}{2\left(d-y_{c}\right)\left[0.6+0.4 \alpha \frac{c_{1}}{c_{3}}+0.4 \frac{c_{2}}{c_{3}} \frac{f_{t}}{\varepsilon_{s . m a x}}\right]} I_{c}
$$

The overall stiffness of cracked R-UHPC beams can be calculated by assembling the macro finite elements (MFE), as shown in Figure 15. The cracked span is determined by the ratio of the applied moment and cracking moment. For the location along the beam where the applied moment is less than the cracking moment, the inertia for the non-cracked section $\left(I_{n c}\right)$ was used. The average moment of inertia $\left(I_{a}\right)$ was applied to the cracked span. The resulting linear system is then solved to calculate the displacement at each node of the meshed beams. Figure 15 shows an example of the simply supported beam under four-point loading. Seven nodes are located in mid-span, quarter-span, and supported sections, and section where the bending moment is equal to the cracking moment. $M_{\mathcal{C}}$ and $M_{a}$ terms correspond to the cracking and applied moments, respectively. 


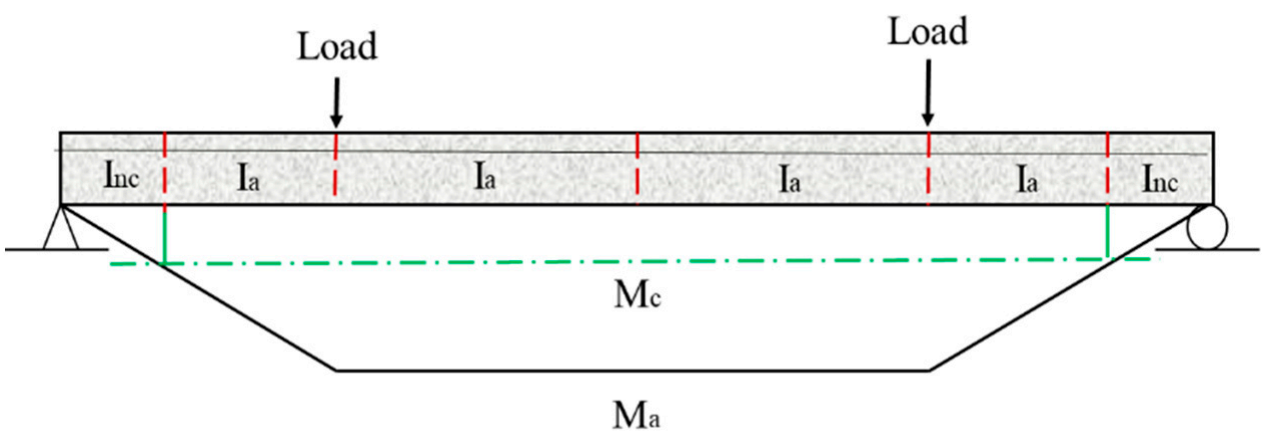

Figure 15. MFE analysis with proposed $I_{a}$ and beam element to evaluate deflection of R-UHPC beams.

The required parameters used in the proposed model are summarized in Table 4.

Table 4. Required parameters in the proposed model.

\begin{tabular}{cc}
\hline Parameters for Cross-Section & Total Depth of Cross-Section $(h)$ \\
\hline Effective depth of cross-section $(d)$ \\
Depth of flange $\left(h_{f}\right)$ \\
Breadth of flange $\left(h_{f}\right)$ \\
Breadth of rib $\left(b_{w}\right)$ \\
Parameters for materials & Area of reinforcing steel $\left(A_{b s}\right)$ \\
\hline Other parameters & Tensile strength of UHPC $\left(f_{t}\right)$ \\
& Elastic modulus of UHPC $\left(E_{c}\right)$ \\
& Elastic modulus of reinforcing bar $\left(E_{s}\right)$ \\
\hline Coefficient of distribution function $\left(C_{H}\right)$ \\
Applied load $(P)$ \\
Span of the beam $(L)$ \\
\hline
\end{tabular}

\subsection{Comparison between Experimental and Calculated Results}

The flexural performance in the service stage was molded in this section. The applied load ranging between $30 \%$ and $70 \%$ of the maximum loading is determined as service load [33]. The $I_{n c}$ is a constant value of $11.85 \times 10^{7} \mathrm{~mm}^{4}$ for the cross-sectional configuration of T-beams. Other bending moment inertias, including those calculated by the developed model $\left(I_{a}\right)$, cracked section $\left(I_{c}\right)$, and ACI model $\left(I_{e}\right)$, are summarized in Table 5 .

Table 5. Neutral axis and calculated inertia for tested beams.

\begin{tabular}{|c|c|c|c|c|c|c|c|c|c|c|c|c|}
\hline \multirow{3}{*}{$\begin{array}{l}\text { Load } \\
(\mathbf{k N})\end{array}$} & \multicolumn{4}{|c|}{ Beam 1} & \multicolumn{4}{|c|}{ Beam 2} & \multicolumn{4}{|c|}{ Beam 3} \\
\hline & $y_{a}$ & $I_{c}$ & $I_{a}$ & $I_{e}$ & $y_{a}$ & $I_{c}$ & $I_{a}$ & $I_{e}$ & $y_{a}$ & $I_{c}$ & $I_{a}$ & $I_{e}$ \\
\hline & $\mathrm{mm}$ & $\begin{array}{l}\left(\times 10^{7}\right. \\
\left.\mathrm{mm}^{4}\right)\end{array}$ & $\begin{array}{l}\left(\times 10^{7}\right. \\
\left.\mathbf{m m}^{4}\right)\end{array}$ & $\begin{array}{l}\left(\times 10^{7}\right. \\
\left.\mathrm{mm}^{4}\right)\end{array}$ & $\begin{array}{l}\left(\times 10^{7}\right. \\
\left.\mathbf{m m}^{4}\right)\end{array}$ & $\begin{array}{l}\left(\times 10^{7}\right. \\
\left.\mathrm{mm}^{4}\right)\end{array}$ & $\begin{array}{l}\left(\times 10^{7}\right. \\
\left.\mathbf{m m}^{4}\right)\end{array}$ & $\begin{array}{l}\left(\times 10^{7}\right. \\
\left.\mathrm{mm}^{4}\right)\end{array}$ & $\begin{array}{l}\left(\times 10^{7}\right. \\
\left.\mathbf{m m}^{4}\right)\end{array}$ & $\begin{array}{l}\left(\times 10^{7}\right. \\
\left.\mathrm{mm}^{4}\right)\end{array}$ & $\begin{array}{l}\left(\times 10^{7}\right. \\
\left.\mathrm{mm}^{4}\right)\end{array}$ & $\begin{array}{l}\left(\times 10^{7}\right. \\
\left.\mathrm{mm}^{4}\right)\end{array}$ \\
\hline 40 & 75.2 & 11.8 & 7.6 & 11.8 & 81.8 & 10.8 & 7.9 & 11.8 & 77.1 & 11.1 & 7.7 & 10.8 \\
\hline 50 & 62.2 & 5.4 & 6.2 & 9.5 & 67.9 & 7.7 & 6.7 & 10.8 & 63.8 & 5.9 & 6.1 & 9.7 \\
\hline 60 & 59.2 & 4.5 & 6.0 & 7.3 & 60.6 & 4.9 & 6.0 & 7.6 & 59.3 & 4.6 & 6.0 & 7.3 \\
\hline 70 & 57.3 & 4.1 & 5.9 & 5.9 & 58.6 & 4.4 & 5.9 & 6.2 & 57.7 & 4.2 & 6.0 & 6.1 \\
\hline 80 & 55.9 & 3.9 & 5.9 & 5.2 & 57.1 & 4.1 & 5.9 & 5.4 & 56.2 & 3.9 & 5.9 & 5.2 \\
\hline 90 & 54.9 & 3.7 & 5.8 & 4.7 & 55.8 & 3.9 & 5.8 & 4.9 & 55.2 & 3.7 & 5.9 & 4.7 \\
\hline 100 & 54.1 & 3.6 & 5.7 & 4.2 & 54.9 & 3.7 & 5.8 & 4.6 & 54.3 & 3.6 & 5.9 & 4.5 \\
\hline
\end{tabular}

As the load increased, the neutral axis moved toward the top of the beam. For example, the distance between the neutral axis and the top of the beam decreased from 75 to $54 \mathrm{~mm}$ with the increase in load from 40 to $100 \mathrm{kN}$. Furthermore, the $I_{e}$ and $I_{\mathcal{C}}$ decreased gradually with the increase in load. For example, the increase in load from 40 to $100 \mathrm{kN}$ led to a decrease in $I_{c}$ and $I_{e}$ from $11.8 \times 10^{7}$ to $3.6 \times 10^{7}$ and $11.8 \times 10^{7}$ to $4.2 \times 10^{7} \mathrm{~mm}^{4}$, 
respectively. On the other hand, the initiation of cracks resulted in the decrease in $I_{a}$. Further increase in load had limited effect on the $I_{a}$. For example, the increased load from 60 to $100 \mathrm{kN}$ led to an approximate $5 \%$ decrease in $I_{a}$ for beam 1 . This can be attributed to the fact that the $I_{a}$ was related to the $I_{c}$, tensile strength of UHPC, and configuration of beams, as shown in Equation (24). As the load increased from 30 to $60 \mathrm{kN}$, the significant reduction in $I_{c}$ from $11.85 \times 10^{7}$ to $4.5 \times 10^{7} \mathrm{~mm}^{4}$ led to a rapid decrease in $I_{a}$ from $11.85 \times 10^{7}$ to $6 \times 10^{7} \mathrm{~mm}^{4}$. When the load further increased from 60 to $100 \mathrm{kN}$, the rate of reduction in $I_{c}$ was decreased. The tensile strength of UHPC had a greater effect on $I_{a}$, which resulted in a limited variation of $I_{a}$.

Figure 16 compares the load-deflection curves obtained by experiments and calculated results using $I_{c}, I_{n c}, I_{a}, I_{e}$, and the MFE model proposed by Castel et al. [23], respectively. The MFE model considers the tension-stiffening effects for the conventional reinforced concrete; however, the effect of fiber on the bridging of cracks was not considered. The predicted and experimental load-deflection responses were compared when the applied loading increased from 0 and $100 \mathrm{kN}$. This is attributed to the fact that the tension-stiffening effect had a limited influence on the overall stiffness of structure after the reinforcing steel yielded [21-23,30,31]. As expected, the deflection was significantly underestimated by using the $I_{n c}$, while the use of $I_{c}$ overestimated the deflection of UHPC. For example, the experimental deflection values were $12.5 \mathrm{~mm}$ at the $100 \mathrm{kN}$ compared to 5.5 and $18 \mathrm{~mm}$ calculated by $I_{n c}$ and $I_{c}$, respectively. Using the $I_{e}$ and the MFE model to estimate deflection led to better results compared to those calculated when using the $I_{c}$ and $I_{n c}$. The deflection calculated by the MFE model was higher than that obtained by the proposed model. This can be attributed to the fact that the effect of fibers on the bridging of cracks was not considered in the MFE model, which underestimates the stiffness of cracked UHPC beam specimens. In general, the developed model resulted in more accurate estimates compared to the other stiffness values $\left(I_{c}, I_{n c}, I_{e}\right.$, and MFE model). This indicates that the tension-stiffening effect should be considered in the deflection prediction of cracked R-UHPC beams.

As shown in Figure 16, as the load increased from 40 to $60 \mathrm{kN}$, the deflection values calculated by the developed model were higher than the experimental results for the three beams. This phenomenon can be attributed to the difference in tensile behavior of UHPC between the real case and the assumed bilinear stress-strain relationship. The simplified model did not consider the stage of strain hardening after initial cracking, which underestimated the stiffness provided by the UHPC when the load increased from 40 to $60 \mathrm{kN}$. On the other hand, for load varying from 70 to $100 \mathrm{kN}$, the calculated deflection values were slightly lower than the experimental results. This can be attributed to the fact that the tensile stress decreased with the increase in tensile strain after peak value. When the assumed constant value of tensile stress of cracked UHPC was higher than the tensile stress in the real case, the model can overestimate the stiffness of cracked UHPC beams.

The values of relative error between the experiments and calculated results are reported in Table 6. Such errors were calculated using the ratio of the difference between experimental and calculated results to the experimental results. The errors from the proposed model are within $15 \%$ of the experimental values, while the errors calculated by the $I_{c}$ and $I_{e}$ varied from $5 \%$ to $30 \%$ and from $5 \%$ to $50 \%$, respectively. This indicates that the deflection of UHPC beams can be accurately predicted by the developed models. When the load was less than $60 \mathrm{kN}$, most of the errors ranged between $10 \%$ and $15 \%$. The errors were less than $10 \%$ at the load varying from 60 to $100 \mathrm{kN}$. This indicates that the developed model slightly underestimated the stiffness at the load ranging from 40 to $60 \mathrm{kN}$. 


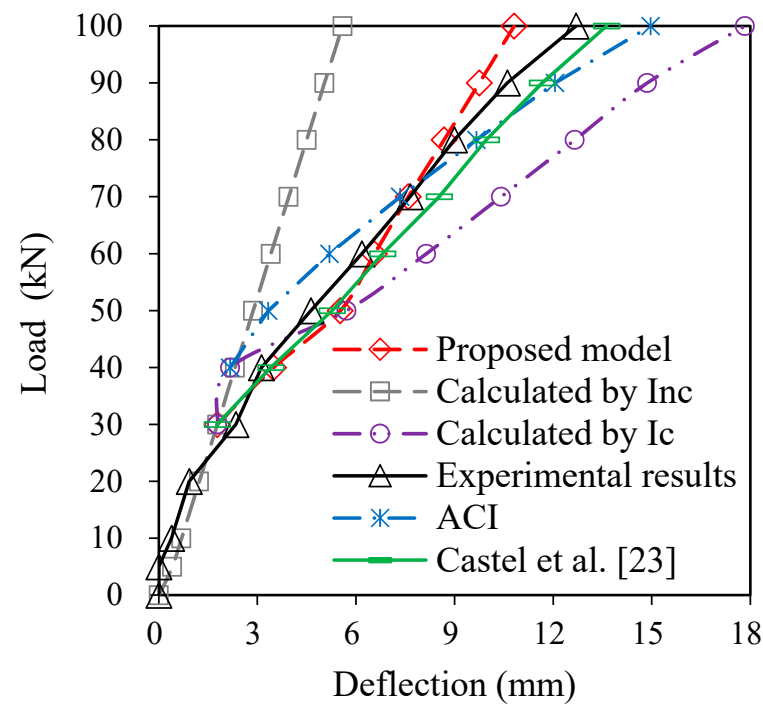

(a)

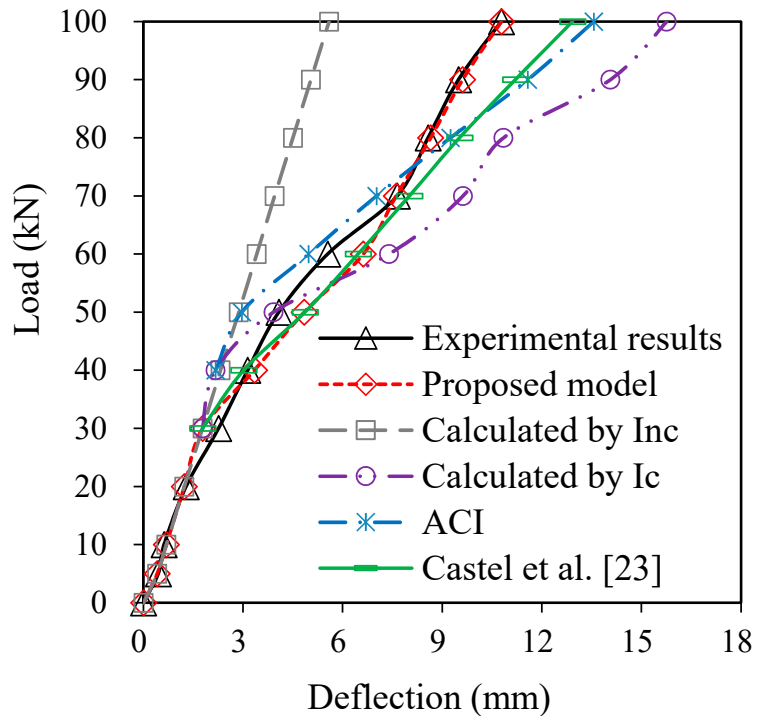

(b)

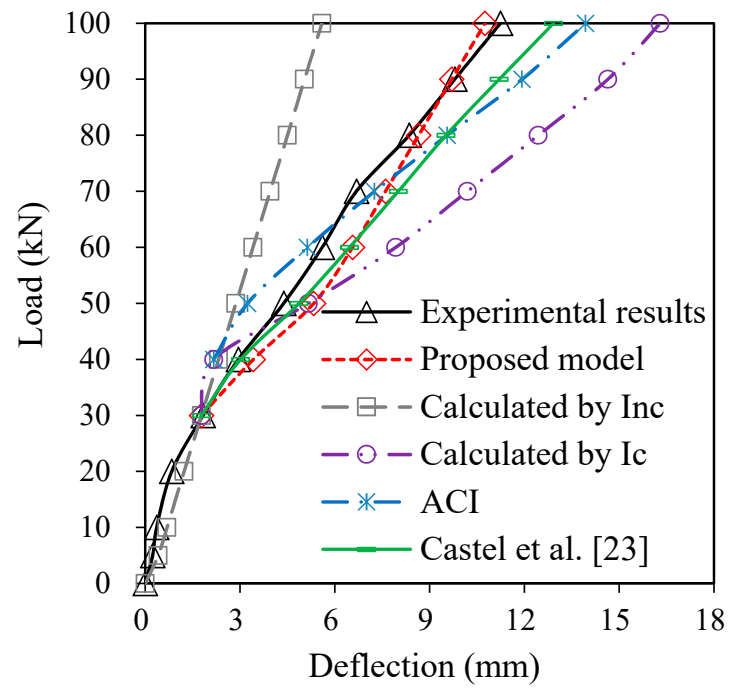

(c)

Figure 16. Load-deflection of cracked R-UHPC beams determined using different theoretical values compared to experimental results: (a) beam 1; (b) beam 2; and (c) beam 3. Green line source: [5].

Table 6. Relative errors between experimental and theoretical deflection values (\%).

\begin{tabular}{cccccccccc}
\hline \multirow{2}{*}{$\begin{array}{c}\text { Load } \\
(\mathbf{k N})\end{array}$} & \multicolumn{3}{c}{ Beam $\mathbf{1}$} & \multicolumn{3}{c}{ Beam $\mathbf{2}$} & \multicolumn{3}{c}{ Beam $\mathbf{3}$} \\
\cline { 2 - 10 } & $\boldsymbol{\Delta ( \boldsymbol { I } _ { \boldsymbol { a } } )}$ & $\boldsymbol{\Delta}\left(\boldsymbol{I}_{\boldsymbol{c}}\right)$ & $\boldsymbol{\Delta}\left(\boldsymbol{I}_{\boldsymbol{e}}\right)$ & $\boldsymbol{\Delta}\left(\boldsymbol{I}_{\boldsymbol{a}}\right)$ & $\boldsymbol{\Delta}\left(\boldsymbol{I}_{\boldsymbol{c}}\right)$ & $\boldsymbol{\Delta}\left(\boldsymbol{I}_{\boldsymbol{e}}\right)$ & $\boldsymbol{\Delta}\left(\boldsymbol{I}_{\boldsymbol{a}}\right)$ & $\boldsymbol{\Delta}\left(\boldsymbol{I}_{\boldsymbol{c}}\right)$ & $\boldsymbol{\Delta}\left(\boldsymbol{I}_{\boldsymbol{e}}\right)$ \\
\hline 40 & 10 & 31 & 31 & 6 & 31 & 31 & 13 & 21 & 26 \\
50 & 15 & 24 & 28 & 14 & 4 & 28 & 15 & 35 & 26 \\
60 & 5 & 32 & 16 & 15 & 33 & 11 & 14 & 39 & 8 \\
70 & 0 & 36 & 4 & 0 & 26 & 8 & 12 & 41 & 8 \\
80 & 3 & 41 & 7 & 1 & 26 & 8 & 3 & 46 & 14 \\
90 & 8 & 40 & 14 & 1 & 48 & 22 & 1 & 49 & 22 \\
100 & 14 & 40 & 18 & 0 & 46 & 25 & 4 & 50 & 24 \\
\hline
\end{tabular}




\subsection{Parametric Study}

Given the similarity of the experiments and deflection results calculated using the proposed model (Equation (24)), the influence of the characteristics of cross-section on flexural performance of R-UHPC beams was investigated. Such characteristics included changes of the $h_{f} / h, b_{f} / h$, and $b_{w} / h$ parameters. The calculated load-deflection curves of UHPC beams prepared with different cross-sectional characteristics are shown in Figure 17. As expected, the increase in $h_{f} / h, b_{f} / h$, or $b_{w} / h$ can enhance the stiffness of the R-UHPC beams of a given depth. For example, the increase in $h_{f} / h$ from 0.1 to 0.3 resulted in a $30 \%$ decrease in deflection for R-UHPC beams under a loading of $90 \mathrm{kN}$. Such decrease in deflection was $35 \%$ when the $b_{f} / h$ increased from 1.5 to 2.5 and then $50 \%$ when the $b_{w} / h$ increased from 0.375 to 0.625 . In general, the increase in $b_{w}$ was the most effective method to enhance the stiffness of R-UHPC beams of a given depth. This can be attributed to the increase in UHPC in the tension zone that can provide greater flexural resistance.

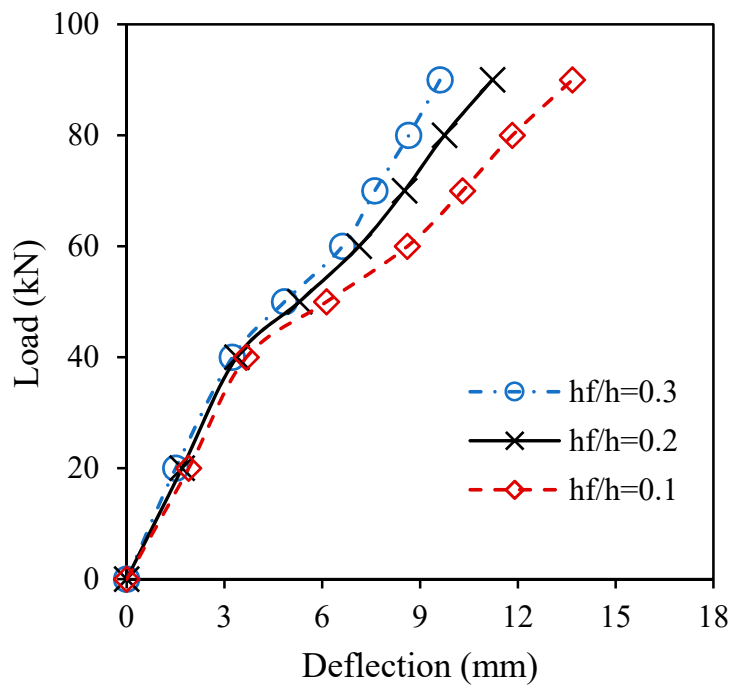

(a)

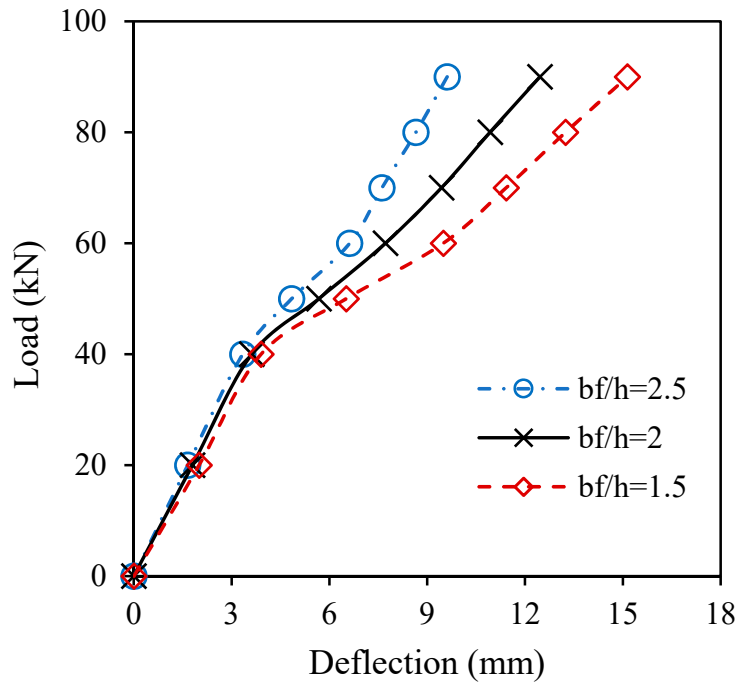

(b)

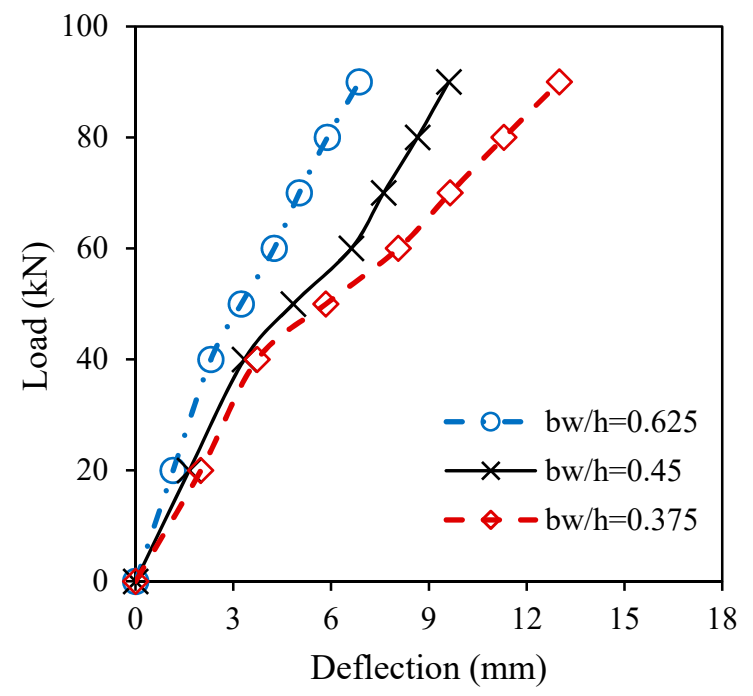

(c)

Figure 17. Effect of cross-sectional characteristics of T-beams on load-deflection curves: (a) $h_{f} / h$; (b) $b_{f} / h$; and (c) $b_{w} / h$. 


\section{Conclusions}

This study developed a model to calculate the flexural deflection of R-UHPC beams with the consideration of the tension-stiffening effect. This model was characterized by the average moment of inertia, which considered bond properties between concrete and reinforcing steel bars and the effect of fibers on crack bridging. Based on the results of experimental and modeled work, the following conclusions can be obtained:

1. The flexural load-deflection response of R-UHPC beams included the elastic stage, cracking stage, and yield stage. In the cracking stage, the fibers can effectively bridge the cracks. The increase in load led to higher crack numbers but a limited increase in crack width from 0.05 to $0.5 \mathrm{~mm}$. Furthermore, the load increased with the deflection with a decreasing slope in this stage. At the yield stage, the fibers were pulled out, resulting in the formation of three or four main cracks and a rapid increase in deflection with the limited change in applied loading.

2. The developed model considering the tension-stiffening effect can successfully predict the deflection of cracked R-UHPC T section beam under service loads. The error of the deflection between the calculated and experimental results can be limited to $15 \%$, while the error calculated by the $I_{\mathcal{c}}$ and $I_{e}$ stiffness value can vary from $5 \%$ to $30 \%$ and from $5 \%$ to $50 \%$, respectively.

3. UHPC beams exhibited closely spaced and narrow cracks at service loads. The tensile strength of the UHPC beam was mainly comprised of non-cracked UHPC, fibers in cracked cross-sections, and reinforcing steel bars.

4. The initiation of cracks resulted in an approximately $20 \%$ decrease in the overall stiffness of R-UHPC beams. However, as the applied loading further increased from $30 \%$ to $70 \%$ of the ultimate loading, a limited reduction in overall stiffness was observed. This can be attributed to the cracking-bridging capacity of fibers.

5. Parametric studies indicated that the increase in breadth of rib had the greatest enhancement on overall stiffness of cracked R-UHPC T section beams, followed by breadth of flange and depth of flange.

\section{Future Work}

The input parameters include the tensile strength of UHPC that can be affected by the fiber orientation and dosage. Therefore, it is worth correlating the tensile strength of UHPC with fiber orientation and dosage to enhance the accuracy of the prediction.

The other valuable topic is to consider the influence of the types of reinforcing steel on the tension-stiffening effect of RC structures. There is a concern that the use of ribbed reinforcing steel might lead to a higher tension-stiffening effect compared to the plain reinforcing steel since the latter one is easier to slip.

Author Contributions: Conceptualization, L.T. and R.Z.; methodology, L.T. and R.Z.; formal analysis, L.T., R.Z., and K.H.K.; investigation, L.T.; R.Z.; writing-original draft preparation, L.T.; writingreview and editing, R.Z. and K.H.K.; visualization, R.Z. and K.H.K.; supervision, R.Z. and K.H.K.; All authors have read and agreed to the published version of the manuscript.

Funding: This project was sponsored by the Program for Changjiang Scholars and Innovative Research Team in University (IRT15R29), Young Elite Scientist Sponsorship Program by CAST, lzjtu EP support (201606), collaborative innovation team of science and technology for colleges and universities in the Gansu Province (2017C-08) and the Long Yuan Youth Innovative Talents Support Programs.

Institutional Review Board Statement: Not applicable.

Informed Consent Statement: Not applicable.

Data Availability Statement: The raw data required to reproduce these findings cannot be shared at this time as the data is a part of the ongoing research.

Acknowledgments: The authors would like to thank Bingzhong Tian at Civil Engineering of Lanzhou Jiaotong University for help in conducting experiments. 
Conflicts of Interest: The authors declare they have no conflict of interest. The funders had no role in the design of the study, in the collection, analyses, or interpretation of data, in the writing of the manuscript, or in the decision to publish the results.

\section{References}

1. Liu, Z.; Chen, X.; Ding, M.; Zhang, X.; Lu, J. Quasi-static test of the gravity railway bridge pier with a novel preventative seismic strengthening technique. Structures 2022, 35, 68-81. [CrossRef]

2. Do, T.V.; Pham, T.M.; Hao, H. Dynamic responses and failure modes of bridge columns under vehicle collision. Eng. Struct. 2018, 156, 243-259. [CrossRef]

3. Fan, L.; Teng, L.; Tang, F.; Khayat, K.H.; Chen, G.; Meng, W. Corrosion of steel rebar embedded in UHPC beams with cracked matrix. Constr. Build. Mater. 2021, 313, 125589. [CrossRef]

4. Fan, L.; Meng, W.; Teng, L.; Khayat, K.H. Effects of lightweight sand and steel fiber contents on the corrosion performance of steel rebar embedded in UHPC. Constr. Build. Mater. 2020, 238, 117709. [CrossRef]

5. Du, J.; Meng, W.; Khayat, K.H.; Bao, Y.; Guo, P.; Lyu, Z.; Abu-obeidah, A.; Nassif, H.; Wang, H. New development of ultra-highperformance concrete (UHPC). Compos. B Eng. 2021, 224, 109220. [CrossRef]

6. Teng, L.; Zhu, J.; Khayat, K.H.; Liu, J. Effect of welan gum and nanoclay on thixotropy of UHPC. Cem. Concr. Res. 2020, 138, 106238. [CrossRef]

7. Teng, L.; Valipour, M.; Khayat, K.H. Design and performance of low shrinkage UHPC for thin bonded bridge deck overlay. Cem. Concr. Compos. 2021, 118, 103953. [CrossRef]

8. Huang, H.; Gao, X.; Teng, L. Fiber alignment and its effect on mechanical properties of UHPC: An overview. Constr. Build. Mater. 2021, 296, 123741. [CrossRef]

9. Yoo, D.-Y.; Kim, S.; Park, G.-J.; Park, J.-J.; Kim, S.-W. Effects of fiber shape, aspect ratio, and volume fraction on flexural behavior of ultra-high-performance fiber-reinforced cement composites. Compos. Struct. 2017, 174, 375-388. [CrossRef]

10. $\mathrm{Wu}, \mathrm{Z}$; Khayat, K.H.; Shi, C. How do fiber shape and matrix composition affect fiber pullout behavior and flexural properties of UHPC? Cem. Concr. Compos. 2018, 90, 193-201. [CrossRef]

11. Yoo, D.-Y.; Kang, S.-T.; Yoon, Y.-S. Effect of fiber length and placement method on flexural behavior, tension-softening curve, and fiber distribution characteristics of UHPFRC. Constr. Build. Mater. 2014, 64, 67-81. [CrossRef]

12. Teng, L.; Meng, W.; Khayat, K.H. Rheology control of ultra-high-performance concrete made with different fiber contents. Cem. Concr. Res. 2020, 138, 106222. [CrossRef]

13. De Maio, U.; Fantuzzi, N.; Greco, F.; Leonetti, L.; Pranno, A. Failure analysis of ultra-high-performance fiber-reinforced concrete structures enhanced with nanomaterials by using a diffuse cohesive interface approach. Nanomaterials 2020, 10, 1792. [CrossRef] [PubMed]

14. Meng, W.; Khayat, K.H. Mechanical properties of ultra-high-performance concrete enhanced with graphite nanoplatelets and carbon nanofibers. Compos. B Eng. 2016, 107, 113-122. [CrossRef]

15. Lampropoulos, A.; Nicolaides, D.; Paschalis, S.; Tsioulou, O. Experimental and numerical investigation on the size effect of Ultra-high-Performance Fibre-Reinforced Concrete (UHFRC). Materials 2021, 14, 5714. [CrossRef]

16. Graybeal, B.A.; Ph, D.; Asce, M. Flexural behavior of an ultrahigh-performance concrete I-girder flexural behavior. J. Bridg. Eng. 2008, 13, 258-270. [CrossRef]

17. Yang, I.H.; Joh, C.; Kim, B.S. Structural behavior of ultra high performance concrete beams subjected to bending. Eng. Struct. 2010, 32, 3478-3487. [CrossRef]

18. Zhu, Y.; Zhang, Y.; Li, X.; Chen, G. Finite element model to predict structural response of predamaged RC beams reinforced by toughness-improved UHPC under unloading status. Eng. Struct. 2021, 235, 112019. [CrossRef]

19. ACI-Committee. Building Code Requirements for Structural Concrete and Commentary; ACI-Committee: Farmington Hills, MI, USA, 2018.

20. CEB-FIP. Structural Concrete: Basis of Design, Updated Knowledge of the CEB-FIP Model Code; CEB-FIP: Lausanne, Switzerland, 1999.

21. Castel, A.; Vidal, T.; Françis, R. Effective tension active cross-section of reinforced concrete beams after cracking. Mater. Struct. Constr. 2006, 39, 115-126. [CrossRef]

22. Castel, A.; Vidal, T.; Françis, R. Finite-element modeling to calculate the overall stiffness of cracked reinforced concrete beams. J. Struct. Eng. 2012, 138, 889-898. [CrossRef]

23. Castel, A.; François, R. Calculation of the overall stiffness and irreversible deflection of cracked reinforced concrete beams. Adv. Struct. Eng. 2013, 16, 2035-2042. [CrossRef]

24. Bischoff, P.H. Tension stiffening and cracking of steel fiber-reinforced concrete. J. Mater. Civ. Eng. 2003, 15, 174-182. [CrossRef]

25. Ganesan, N.; Indira, P.V.; Sabeena, M.V. Tension stiffening and cracking of hybrid fiber-reinforced concrete. ACI Mater. J. 2013, $110,715-721$.

26. Lee, S.C.; Cho, J.Y.; Vecchio, F.J. Tension-stiffening model for steel fiber-reinforced concrete containing conventional reinforcement. ACI Struct. J. 2013, 110, 639-648.

27. Meng, W.; Valipour, M.; Khayat, K.H. Optimization and performance of cost-effective ultra-high performance concrete. Mater. Struct. Constr. 2017, 50, 1-16. [CrossRef] 
28. Zhou, Y.; Xi, B.; Yu, K.; Sui, L.; Xing, F. Mechanical properties of hybrid ultra-high performance engineered cementitous composites incorporating steel and polyethylene fibers. Materials 2018, 11, 1448. [CrossRef]

29. Aaleti, S.; Petersen, B.; Sritharan, S. Design Guide for Precast UHPC Waffle Deck Panel System, Including Connections; No. FHWA-HIF13-032; Federal Highway Administration: Washington, DC, USA, 2013.

30. Castel, A.; François, R. Modeling of steel and concrete strains between primary cracks for the prediction of cover-controlled cracking in RC-beams. Eng. Struct. 2011, 33, 3668-3675. [CrossRef]

31. Xu, T.; Castel, A. Modeling the dynamic stiffness of cracked reinforced concrete beams under low-amplitude vibration loads. J. Sound Vib. 2016, 368, 135-147. [CrossRef]

32. Yang, H.; Joh, C.; Kim, B.-S. Flexural strength of large-scale ultra high performance concrete prestressed T-beams. Can. J. Civ. Eng. 2011, 38, 1185-1195. [CrossRef]

33. Graybeal, B.A.; Baby, F. Development of direct tension test method for ultra-high-performance fiber-reinforced concrete. ACI Mater. J. 2013, 110, 177.

34. François, R.; Castel, A.; Vidal, T. A finite macro-element for corroded reinforced concrete. Mater. Struct. Constr. 2006, 39, 571-584. [CrossRef]

35. Murray, A.; Gilbert, R.I.; Castel, A. Spacing of cracks in reinforced concrete based on a variable transfer length model. J. Struct. Eng. 2018, 144, 1-10. [CrossRef]

36. Meng, W.; Khayat, K.H. Effect of hybrid fibers on fresh properties, mechanical properties, and autogenous shrinkage of costeffective UHPC. J. Mater. Civ. Eng. 2018, 30, 04018030. [CrossRef]

37. Huang, H.; Gao, X.; Khayat, K.H.; Su, A. Influence of fiber alignment and length on flexural properties of UHPC. Constr. Build. Mater. 2021, 290, 122863. [CrossRef]

38. Teng, L.; Huang, H.; Du, J.; Khayat, K.H. Prediction of fiber orientation and flexural performance of UHPC based on suspending mortar rheology and casting method. Cem. Concr. Compos. 2021, 122, 104142. [CrossRef] 